\title{
Visfatin: An adipokine activator of rat hepatic stellate cells
}

\author{
NING-LIN LIANG $^{1}$, RUOTING MEN ${ }^{1}$, YONGJUN ZHU ${ }^{1}$, CONG YUAN $^{1}$, \\ YAN WEI ${ }^{1}$, XIAOJING LIU ${ }^{2}$ and LI YANG $^{1}$ \\ ${ }^{1}$ Department of Gastroenterology; ${ }^{2}$ Laboratory of Cardiovascular Diseases, West China Hospital, \\ Sichuan University, Chengdu, Sichuan 610041, P.R. China
}

Received December 22, 2013; Accepted September 29, 2014

DOI: $10.3892 / \mathrm{mmr} .2014 .2795$

\begin{abstract}
The present study was conducted to investigate the effects of visfatin on the activation of hepatic stellate cells (HSC) and the possible underlying mechanism. HSC were isolated from the livers of Sprague-Dawley rats by in situ perfusion of collagenase and pronase and a single-step density Nycodenz gradient. The culture-activated cells were serum-starved and incubated with different concentrations of recombinant visfatin $(0,25,50,100$ or $200 \mathrm{ng} / \mathrm{ml})$ for $24 \mathrm{~h}$. The expression of $\alpha$-smooth muscle actin ( $\alpha$-SMA), collagen types I and III and connective tissue growth factor (CTGF) were then measured by reverse transcription-quantitative polymerase chain reaction ( $\mathrm{RT}-\mathrm{qPCR}$ ) and western blot analysis. The results demonstrated that 100 and $200 \mathrm{ng} / \mathrm{ml}$ concentrations of visfatin induced the expression of $\alpha$-SMA in culture-activated rat HSC, which was accompanied by a significant increase in collagen types I and III, as confirmed by western blot and RT-qPCR analyses. In addition, treatment of the HSC with certain concentrations of visfatin upregulated the expression of CTGF. These findings suggested that visfatin activated HSC and induced the production of collagen types I and III.
\end{abstract}

\section{Introduction}

In the past decade, an increasing number of studies have demonstrated the involvement of various adipokines in the process of liver cirrhosis, of which the most important are leptin (1), adiponectin (2), tumor necrosis factor- $\alpha$, resistin and interleukin-6 $(3,4)$. Visfatin, a novel adipokine which has insulin-like effects, regulates inflammatory and immunomodulatory processes $(5,6)$ and catalyzes the rate-limiting step in the production of nicotinamide adenine dinucleotide from nicotinamide. Previous studies have identified the potential effects of visfatin on the proliferation and collagen synthesis of rat cardiac

Correspondence to: Professor Li Yang, Department of Gastroenterology, West China Hospital, Sichuan University, 37 Guoxue Street, Chengdu, Sichuan 610041, P.R. China

E-mail: linayang63@gmail.com

Key words: visfatin, hepatic stellate cell, $\alpha$-smooth muscle actin, collagen type I, collagen type III, connective tissue growth factor fibroblasts (7). Visfatin is involved in perivascular adipose tissue-induced vascular smooth muscle cell proliferation (8) and the increased synthesis of profibrotic molecules, including transforming growth factor-1 (TGF-1) and plasminogen activator inhibitor-1 (9). Therefore, there is convincing evidence to suggest that visfatin is involved in the initiation and progression of fibrosis.

Hepatic stellate cells (HSC) are liver mesenchymal cells located in the space of Disse, in close contact with sinusoidal endothelial cells and hepatocytes (10). The process of quiescent HSC activation into contractile myofibroblasts is an important step during liver fibrogenesis (11). Quiescent HSC can transdifferentiate into $\alpha$-smooth muscle actin ( $\alpha$-SMA)-positive activated myofibroblast-like cells, which produce a wide variety of collagenous and noncollagenous extracellular matrix (ECM) proteins. Increased collagen deposition leads to the accumulation of ECM, which is the major cause of liver dysfunction during hepatic fibrosis (12).

The association between visfatin and the activation of HSC, the key event in fibrogenesis, remains to be elucidated. In the present study, culture-activated HSC were treated with visfatin. The mRNA and protein expression levels of $\alpha$-SMA, collagen types I and III and connective tissue growth factor (CTGF) were then determined using reverse transcription quantitative polymerase chain reaction (RT-qPCR) and western blot analyses.

\section{Materials and methods}

Cell culture. Primary cultures of HSC were isolated from the livers of eight healthy male Sprague-Dawley rats (10-12 weeks old, weighing 450-500 g), which were obtained from the Animal Center of Sichuan University (Sichuan, China), by in situ pronase and collagenase perfusion (13) and a single step Nycodenz gradient according to previous studies by our group $(10,14)$. The HSC were maintained in Dulbecco's modified Eagle's medium (DMEM; Gibco-BRL, Grand Island, NY, USA) supplemented with $10 \%$ fetal bovine serum (FBS; HyClone, Logan, UT, USA), $2 \mathrm{mmol} / \mathrm{l} \mathrm{L-glutamine} \mathrm{(Gibco-BRL)} \mathrm{and} \mathrm{1 \%} \mathrm{penicillin-strepto-}$ mycin (KeLong Chemical Co., Ltd., Chengdu, China). All cell cultures were maintained in a humidified $5 \% \mathrm{CO}_{2} / 95 \%$ air incubator at $37^{\circ} \mathrm{C}$. The primary HSC were identified by assessing the expression of desmin and their activation was determined by the level of expression of the specific marker, $\alpha$-smooth muscle actin ( $\alpha$-SMA). The present study was approved by the 
Medical Ethics Committee of the West China Hospital, Sichuan University (Chengdu, China).

Based on previous studies $(7,9,15,16)$, experimental concentrations of $0,25,50,100$ and $200 \mathrm{ng} / \mathrm{ml}$ visfatin were selected for the present study. Subsequently, HSC at $90 \%$ confluence in the culture dishes were serum-starved for $24 \mathrm{~h}$ followed by treatment with different concentrations of visfatin $(25,50,100$ or $200 \mathrm{ng} / \mathrm{ml}$; Enzo Biochemical Co., Inc., Farmingdale, NY, USA) for $24 \mathrm{~h}$ with the exception of an untreated group as the control. All animal investigations were approved by the Ethics Committee for Animal Care of Sichuan University (Chengdu, China).

Immunocytochemistry. For immunocytochemical staining, the HSC were cultured on coverslips in six-well plates $\left(1 \times 10^{5}\right.$ cells/well). The cells were fixed by incubation with $4 \%$ paraformaldehyde in phosphate-buffered saline (PBS) for $20 \mathrm{~min}$ stored at $4^{\circ} \mathrm{C}$ followed by washing in PBS three times. The cells were then rinsed in $0.1 \%$ Triton X-100 (Kelong Chemical Co., Ltd.) in PBS for 15 min at room temperature (RT), washed three times in PBS and incubated with $10 \%$ goat serum (Gibco-BRL) for $1 \mathrm{~h}$ to block non-specific binding sites. The coverslips were incubated with the primary antibodies monoclonal rabbit anti-rat $\alpha$-SMA (Abcam, Cambridge, UK) or polyclonal rabbit anti-rat desmin (Santa Cruz Biotechnology, Inc., Dallas, TX, USA) at working dilutions of 1:100 at $4^{\circ} \mathrm{C}$ overnight. Negative controls were included by incubation with goat serum (Gibco-BRL) corresponding to the primary antibody. Following rinsing three times with PBS, the secondary biotinylated goat anti-rabbit secondary antibody (1:200; Zhonshan Jinquai Biotechnology Co., Ltd., Beijing, China) was applied and incubated at room temperature for $2 \mathrm{~h}$. Color development was performed using a DBA kit (Zhonshan Jinquai Biotechnology Co., Ltd.) as previously described (17). A microscope (TH4-200; Olympus, Tokyo, Japan) was then used for image capture.

$R T-q P C R$. Total RNA from the HSC was isolated using TRIzol reagent (Invitrogen Life Technologies, Carlsbad, CA, USA) according to the manufacturer's instructions and the purity and content of total RNA were determined by spectrophotography (SmartSpec Plus; Bio-Rad, Hercules, CA, USA). The A260/A280 ratio of total RNA was between 1.8 and 2.0. For the first-strand cDNA synthesis, $1 \mu \mathrm{g}$ total RNA was used in each sample using an RT kit (ReverTra Ace; Toyobo, Osaka, Japan) according to the manufacturer's instructions. qPCR was performed on a Bio-Rad real-time PCR system (CFX96; Bio-Rad, Hercules, CA, USA) using the fluorescent dye SYBR-Green I(SYBR-Green Real-time PCR Master mix; Toyobo). The sequences of the primers used were as follows: $\alpha$-SMA forward, 5'-CCG AGA TCT CAC CGA CTA CC-3' and reverse, 5'-TCC AGA GCG ACA TAG CAC AG-3'; collagen I $(\alpha 1)$ forward, 5'-ACG TCC TGG TGA AGT TGG TC-3' and reverse, 5'-TCC AGC AAT ACC CTG AGG TC-3' (18); collagen III $(\alpha 1)$ forward, 5'-TCC TCT GTG ATG ACA TAA TGT GTG-3' and reverse, 5'-GTA GAA GGC TGT GGA CAT ATT GC-3' (19); CTGF forward, 5'-CAG GGA GTA AGG GAC ACG A-3' and reverse, 5'-ACA GCA GTT AGG AAC CCA GAT-3' (20) and $\beta$-actin forward, 5'-ACT ATC GGC AAT GAG CGG TTC-3' and reverse, 5'-ATG CCA CAG GAT TCC ATA CCC-3'. The primers was provided by Invitrogen
Life Technologies. The amplification conditions for each sample were as follows: $95^{\circ} \mathrm{C}$ for $1 \mathrm{~min}$ and 40 cycles of $95^{\circ} \mathrm{C}$ for $15 \mathrm{sec}$ and $60^{\circ} \mathrm{C}$ for $40 \mathrm{sec}$. The fluorescence resulting from the incorporation of SYBR-Green I into the double-stranded DNA was detected at the end of the elongation phase of each PCR cycle using an RT-qPCR detection system (CFX96; Bio-Rad). Each gene was standardized against the housekeeping gene $\beta$-actin. The mRNA levels were expressed as a ratio, using the $2^{-\Delta \Delta C T}$ method with Bio-Rad software (Quantity One 4.62; Bio-Rad), for comparing the relative mRNA expression levels between different groups in the qPCR.

Western blot analysis. The treated HSC were lysed with radioimmunoprecipitation assay buffer containing $50 \mathrm{mM}$ Tris- $\mathrm{HCl}$ (pH 7.4), $150 \mathrm{mM} \mathrm{NaCl}, 1 \%$ NP-40, $0.1 \%$ SDS and the protease inhibitor cocktail cOmplete Mini (Roche Diagnostics $\mathrm{GmbH}$, Mannheim, Germany). The protein concentrations were determined using a bicinchoninic acid protein assay kit (Pierce Biotechnology, Inc., Rockford, IL, USA). The total proteins from the cell lysate $(30 \mu \mathrm{g})$ were separated by $10 \%$ SDS-PAGE by electrophoresis and then transferred onto a $0.45-\mu \mathrm{m}$ nitrocellulose membrane (Roche Diagnostics). The membranes were inhibited by agitation in 5\% fat-free milk in tris-buffered saline-Tween 20 (TBS-T; KeLong Chemical Co., Ltd.) buffer for $2 \mathrm{~h}$ at RT and subsequently incubated overnight at $4^{\circ} \mathrm{C}$ with the following primary antibodies: Rabbit anti-rat $\alpha$-SMA polyclonal antibody (1:1,000; Abcam), mouse anti-rat collagen type I monoclonal antibody (1:200), goat anti-rat collagen type III polyclonal antibody (1:200), goat anti-rat CTGF polyclonal antibody (1:200) and mouse anti-rat $\beta$-actin monoclonal antibody $(1: 2,000)$ all from Santa Cruz Biotechnology, Inc. The membranes were then washed with TBS-T buffer and incubated with horseradish peroxidase-conjugated secondary antibody (1:3,000 in TBST with 5\% skim milk) at room temperature for $2 \mathrm{~h}$ (Zhonshan Jinquai Biotechnology Co., Ltd.). The bands were detected using an enhanced chemiluminescence detection kit (ECL kit; Pierce Biotechnology, Inc.).). Optical densities of the bands were scanned and quantified using the Gel Doc 2000 system (Bio-Rad). $\beta$-actin was used as a loading control.

Statistical analysis. Data are expressed as the mean \pm standard error of the mean. Each experiment was repeated three times. Group means were compared by one-way analysis of variance using the statistical software program SPSS 18.0 for Windows (International Business Machines, Armonk, NY, USA). P<0.05 was considered to indicate a statistically significant difference.

\section{Results}

HSC culture activation and identification. By culturing quiescent HSC on uncoated plastic culture wells, spontaneous activation was induced, mimicking the process observed in vivo, and providing a suitable model for investigating the relative factors involved in HSC activation and its underlying mechanisms (21). A number of techniques can be used to assist in the identification of HSC. The expression of desmin and $\alpha$-SMA remain useful methods for identifying primary and activated HSC in vitro (22). In the present study, the cells were stained for desmin, which is a marker of HSC that is positive in rodent HSC regardless of activation status (23). 
A

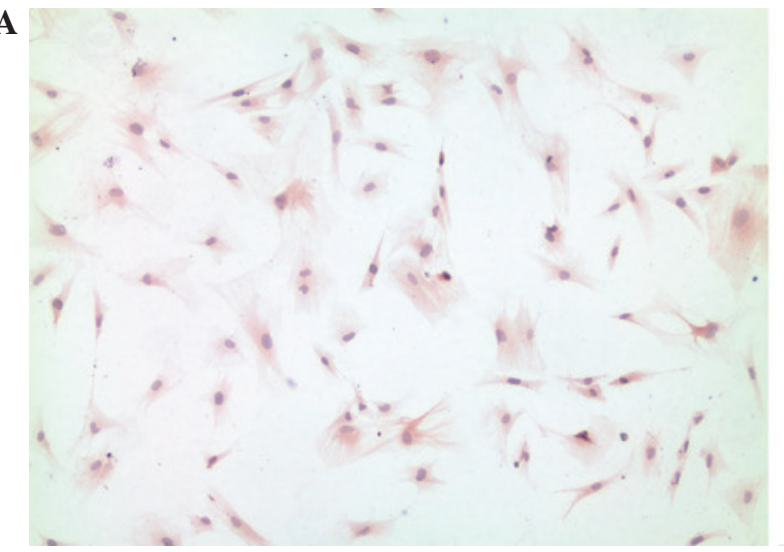

B

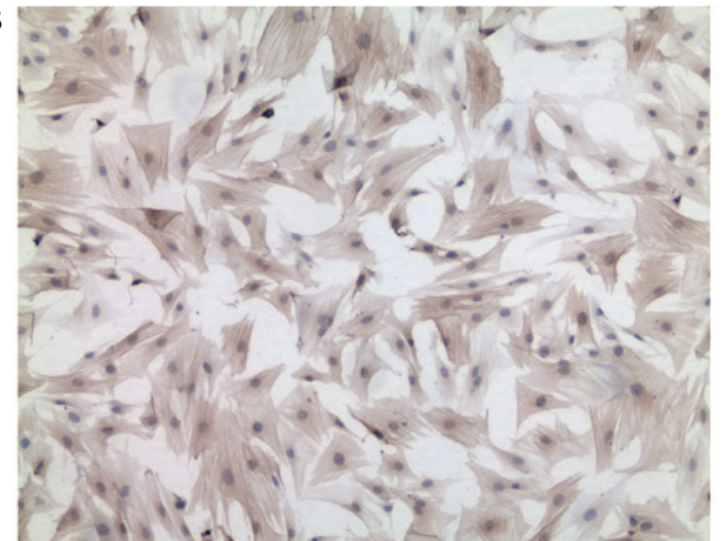

Figure 1. Immunocytochemical staining of desmin and $\alpha$-SMA in HSC. (A) Immunocytochemical staining for desmin in HSC cultured for 7 days following isolation; (B) immunocytochemical staining for $\alpha$-SMA in cultured-activated HSC. (Original magnification, x100); scale bars, $1 \mu \mathrm{m}$ ). $\alpha$-SMA, $\alpha$-smooth muscle actin; HSC, hepatic stellate cells.
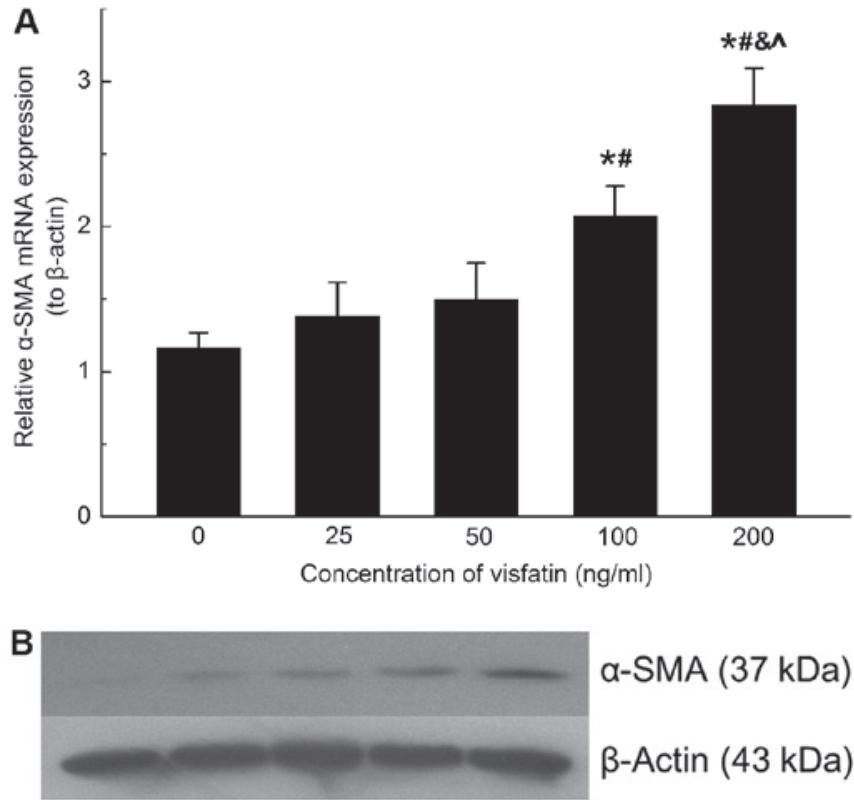

a-SMA (37 kDa)

$\beta$-Actin (43 kDa)

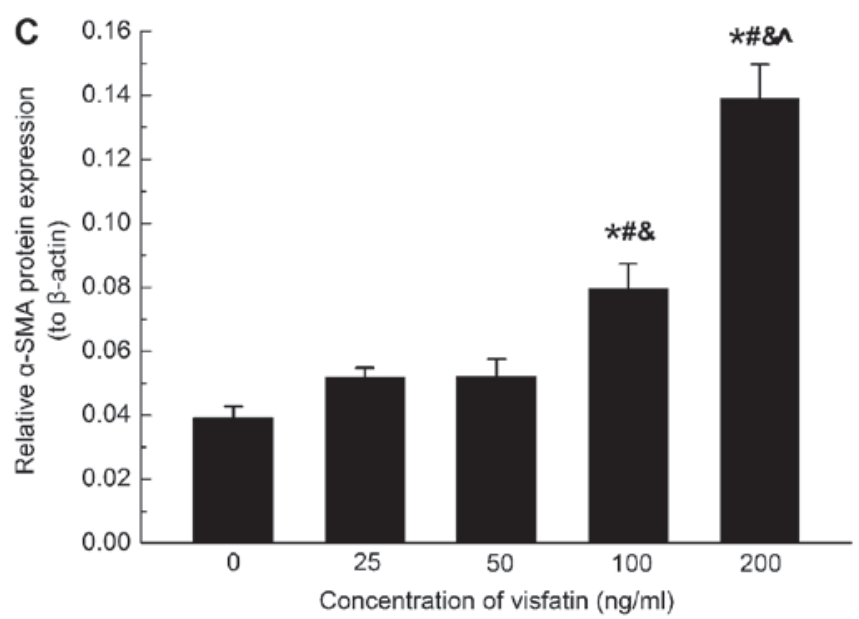

Figure 2. Visfatin increases the mRNA expression and protein production of $\alpha$-SMA in HSC. (A) Visfatin increases gene and (B and C) protein expression of $\alpha$-SMA in activated HSC in a dose-dependent manner. Experiments were performed in triplicate. For the quantitative polymerase chain reaction, values were normalized to $\beta$-actin. For western blot analyses, $\beta$-actin was used as an internal control. Error bars represent standard deviation. ${ }^{*, \#, \&, \wedge} \mathrm{P}<0.05$, vs. 0 , 25,50 and $100 \mathrm{ng} / \mathrm{ml}$ visfatin groups, respectively. $\alpha$-SMA $\alpha$-smooth muscle actin; HSC, hepatic stellate cells.
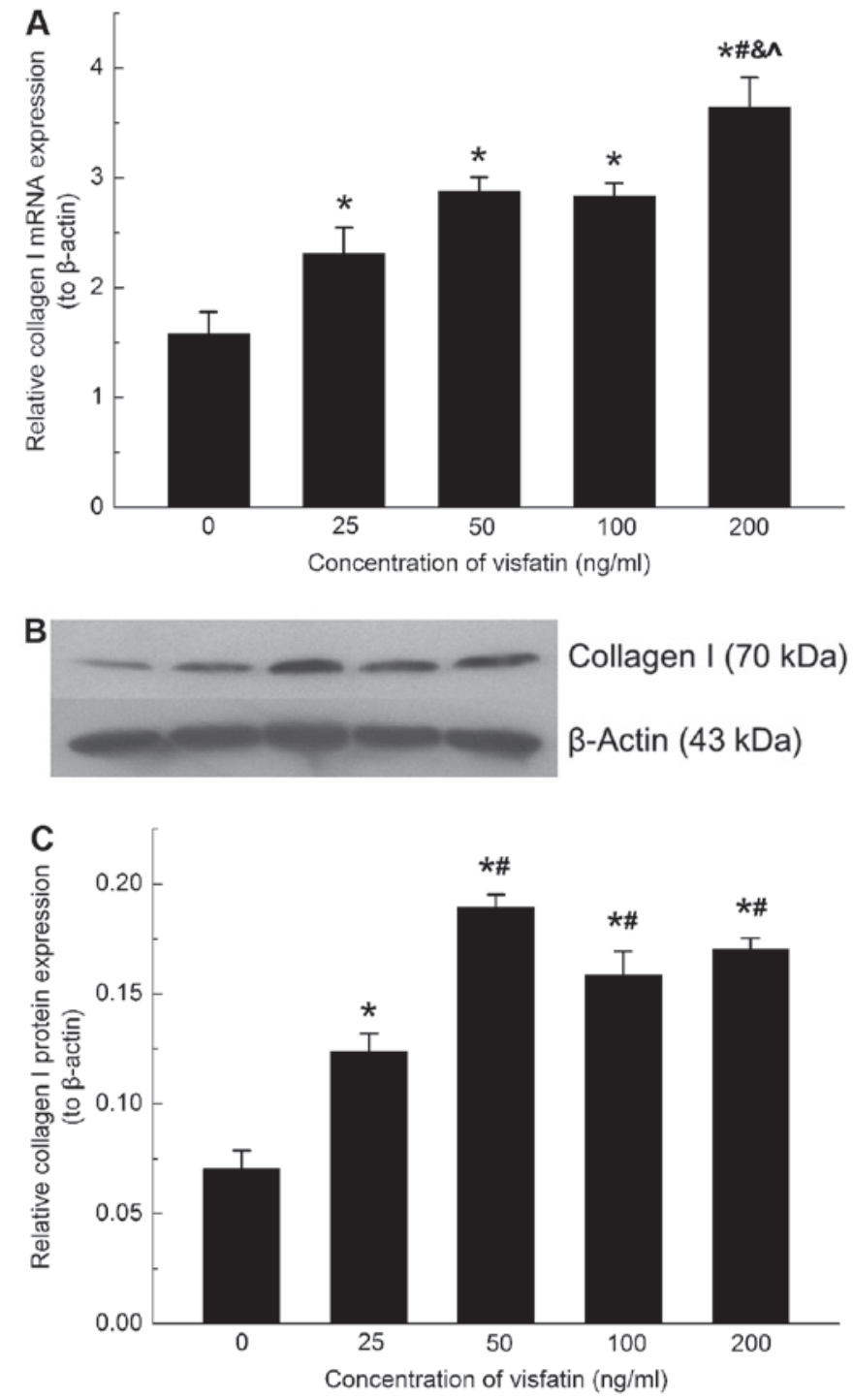

Figure 3. Addition of exogenous visfatin increases the (A) mRNA expression and (B and $\mathrm{C}$ ) protein production of collagen type I in activated hepatic stellate cells. For quantitative polymerase chain reaction, $\beta$-actin was used as an invariant control for calculating fold-changes in mRNA. For western blot analyses, $\beta$-actin was used as an internal control for equal

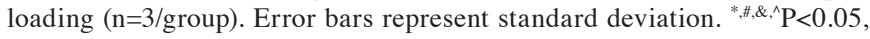
vs. $0,25,50$ and $100 \mathrm{ng} / \mathrm{ml}$ visfatin groups, respectively. 


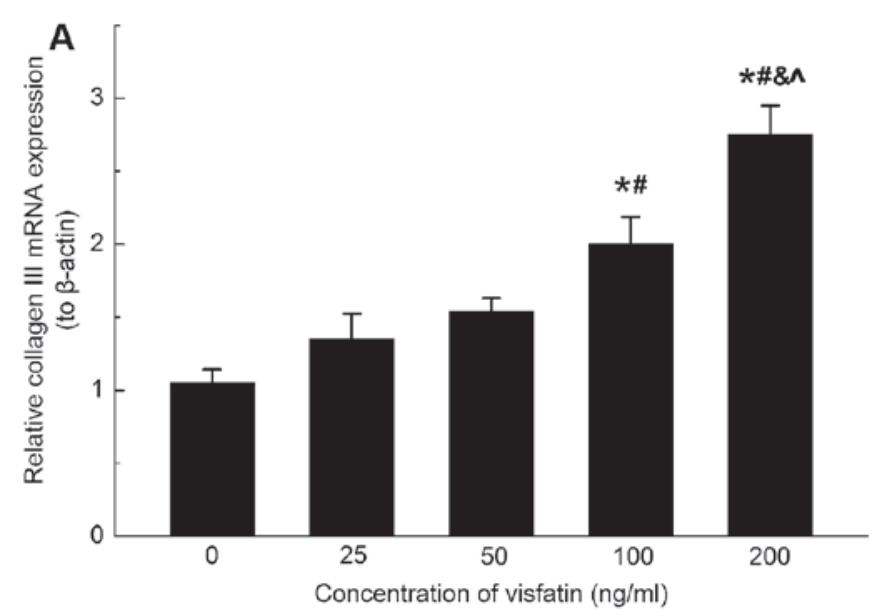

B
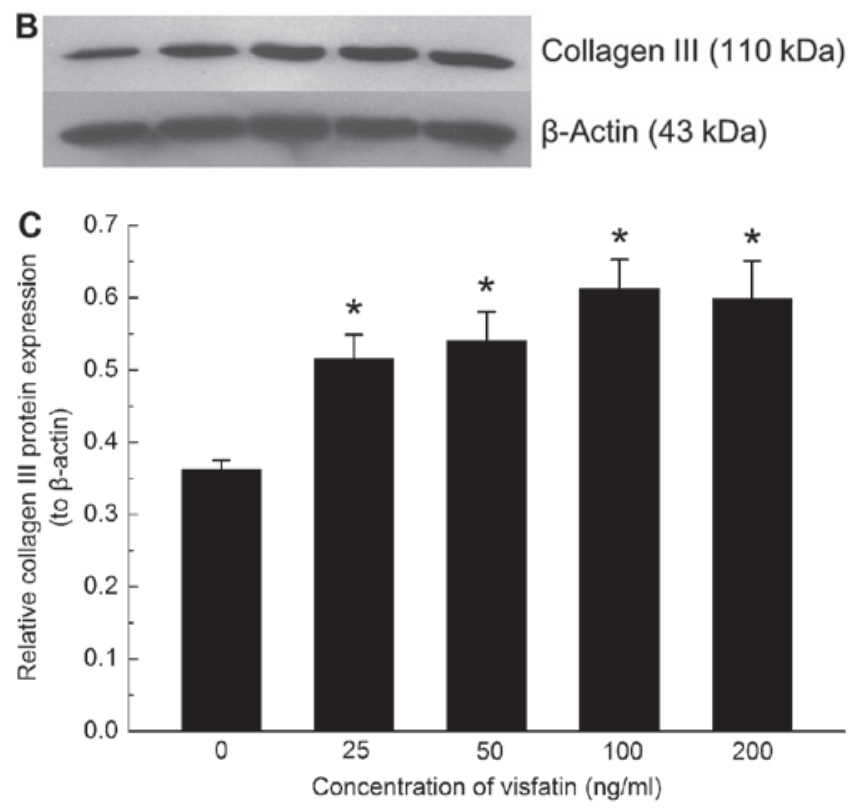

Figure 4. Visfatin increases the (A) gene and (B and C) protein expression of collagen type III $(\alpha 1)$ in hepatic stellate cells. Experiments were performed three times with similar results ( $\mathrm{n}=3$ /group). Error bars represent standard deviation. ${ }^{*, \#, \&, \wedge} \mathrm{P}<0.05$, vs. $0,25,50$ and $100 \mathrm{ng} / \mathrm{ml}$ visfatin groups, respectively.

The immunocytochemical staining by desmin suggested that, by day 7 of culturing, HSC accounted for $>90 \%$ of the cells in the cultures (Fig. 1A). The passaged cells were also stained for $\alpha$-SMA, a marker of activated stellate cell phenotypes. The passaged cells were markedly positive for $\alpha$-SMA (Fig. 1B).

Visfatin upregulates the $M R N A$ and protein expression of $\alpha$-SMA in HSC. The expression of $\alpha$-SMA is a reliable marker of HSC activation. To determine whether visfatin had modulatory effects on the expression of $\alpha$-SMA in HSC, the rat HSC were treated with different concentrations of visfatin for $24 \mathrm{~h}$. The results demonstrated that 100 and $200 \mathrm{ng} / \mathrm{ml}$ visfatin evoked significant expression of $\alpha$-SMA in the HSC compared with the control group. Additionally, $200 \mathrm{ng} / \mathrm{ml}$ visfatin had a more marked effect on inducing the gene and protein expression of $\alpha$-SMA compared with $100 \mathrm{ng} / \mathrm{ml}$ visfatin (Fig. 2).
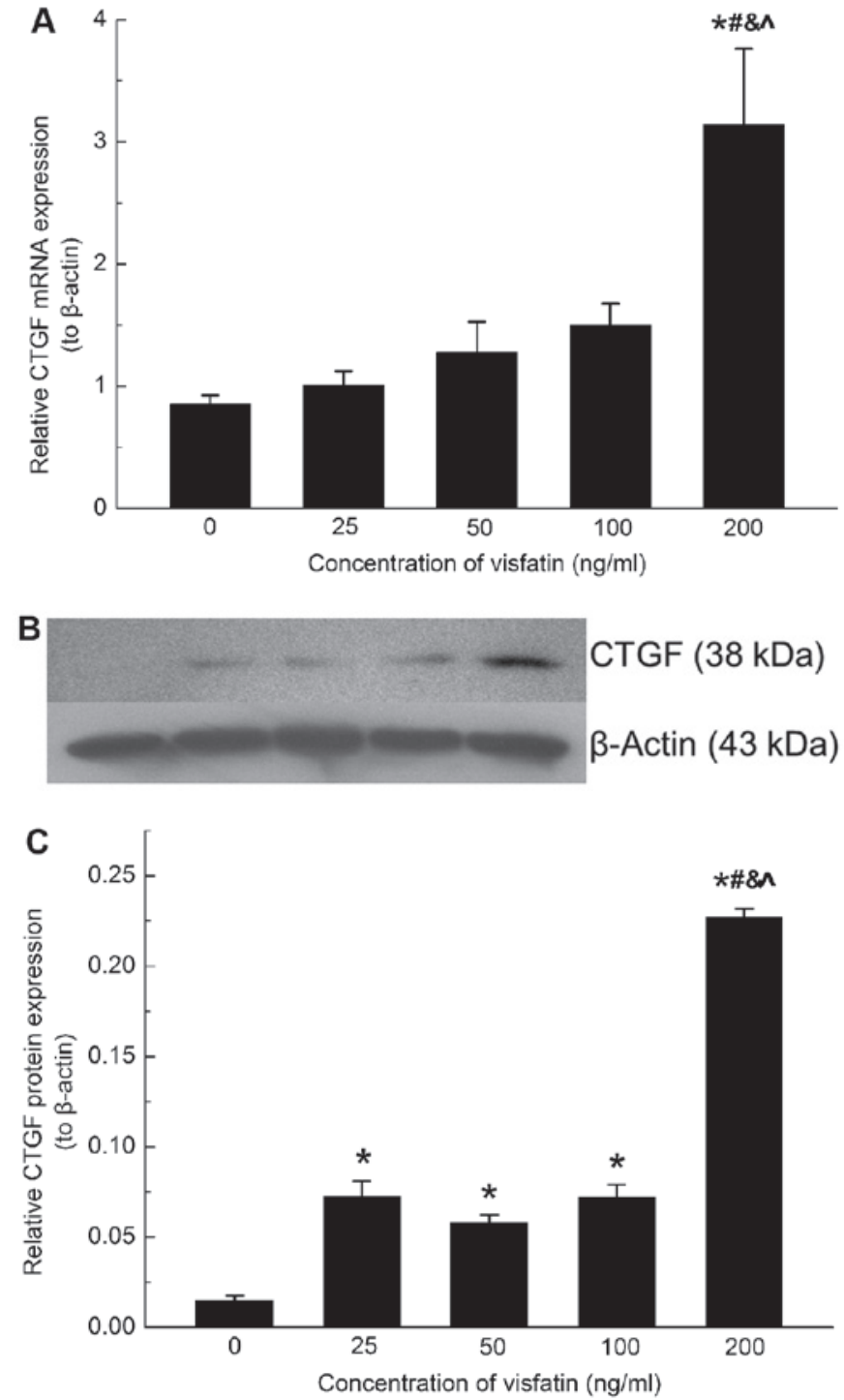

Figure 5. Visfatin induces the (A) mRNA and (B and C) protein expression of CTGF in hepatic stellate cells. Experiments were performed three times with similar results ( $n=3 /$ group). Error bars represent standard deviation. ${ }^{*, \#, \&, \wedge} \mathrm{P}<0.05$, vs. $0,25,50$ and $100 \mathrm{ng} / \mathrm{ml}$ visfatin groups, respectively. CTGF, connective tissue growth factor.

Visfatin increases collagen production in HSC. When activated, HSC transform into myofibroblast-like cells and produce substantial quantities of ECM proteins, including collagen, fibronectin, undulin, elastin, laminin, hyaluronan and proteoglycans (24). The accumulation of ECM proteins distorts the hepatic architecture by forming fibrous scars and the subsequent development of nodules in the regenerating hepatocytes produces cirrhosis (25).

To determine whether visfatin affected the process of liver fibrogenesis through upregulating the secretion of ECM, the expression of collagen types I and III in the HSC was assessed following treatment with different concentrations of visfatin.

The mRNA expression levels of collagen types I and III were increased upon visfatin stimulation (Figs. 3A and 4A). To further confirm the effects of visfatin on the protein regulation of collagen types I and III, the present study also examined the production of protein. The western blot analysis revealed that visfatin induced a significant elevation in the protein accumu- 
lation of collagen types I and III in the HSC (Figs. 3B and 4B). These data indicated that visfatin was involved in the upregulation of ECM secretion in the HSC.

Visfatin induces the expression of CTGF in HSC. CTGF is regarded as the main downstream mediator of the fibrogenic master cytokine TGF- $\beta$ and has been implicated in the pathogenesis of hepatic fibrosis (26). In HSC, CTGF is important in the transition of HSC to myofibroblast-like cells and stimulates the synthesis of ECM protein (23). In the present study, to determine whether CTGF was regulated in response to visfatin, the gene and protein expression of CTGF was analyzed in the HSC upon treatment with different concentrations of visfatin. Only the concentration of $200 \mathrm{ng} / \mathrm{ml}$ visfatin increased the mRNA expression of CTGF mRNA after $24 \mathrm{~h}$ of treatment (Fig. 5A), however, the protein expression of CTGF was significantly induced at all experimental concentrations of visfatin (Fig. 5B). These inconsistencies in mRNA and protein upregulation may be due to post-transcriptional regulation.

\section{Discussion}

The present study identified several significant findings: Visfatin upregulated the gene and protein production of $\alpha$-SMA, a marker of HSC activation; visfatin increased the mRNA and protein expression of collagen types I and III in the HSC and the production of CTGF was increased following exposure to visfatin. These observations established the possibility that CTGF mediated the visfatin-induced activation of HSC and it is therefore suggested that visfatin may be involved in liver fibrogenesis.

The interaction between various adipokines, including asleptin and adiponectin, is important in the process of hepatic fibrogenesis (3). Leptin can directly target HSC via activation of its receptor and all the features of activated HSC are modulated by leptin in a profibrogenic manner (4). Lower levels of leptin in quiescent HSC are associated with increased expression of adiponectin, an antifibrogenic factor (27). Adiponectin-knockout mice exhibited more extensive fibrosis compared with wild-type animals following chronic $\mathrm{CCl}_{4}$ intoxication (28). Visfatin is a recently identified adipokine, which is produced and secreted mainly by visceral adipose tissue. It can induce the proliferation of various cell types, including human umbilical vein endothelial cells $(29,30)$, vascular smooth muscle cells (8) and human osteoblasts (31). However, the roles of visfatin in HSC activation, which may induce HSC proliferation, remain to be elucidated. To the best of our knowledge, the present study was the first to observe that visfatin promoted the expression of $\alpha$-SMA in HSC and provided direct evidence that visfatin may be involved in the activation of HSC.

When activated, HSC lose their retinoid shape, begin to proliferate and the process of ECM synthesis begins to produce fibrous scar tissue (32). Collagen types I and III are the main components of the resulting ECM. In the present study, collagen types I and III were induced upon visfatin stimulation, indicating that visfatin may be involved in processes of liver fibrogenesis.

Previous pilot studies have confirmed induction of the mRNA and protein production of CTGF in cultured HSC in response to visfatin (33). HSC are the major cellular source of CTGF in the liver during hepatic fibrogenesis (34). CTGF can be regulated by TGF- $\beta$ and is important in the overproduction of ECM in activated HSC (35). The mRNA levels of CTGF were markedly increased in cultured HSC and fibrotic livers and the curcumin-induced inhibition of collagen type I gene expression in activated HSC correlates with suppression in the gene expression of CTGF (36). Knocking down CTGF by small interfering RNA inhibited the expression of carbon tetrachloride-induced collagen in HSC and in liver fibrosis (37). Certain biological functions of CTGF, including the induction of cell adhesion, migration, proliferation and DNA synthesis, may explain the visfatin-induced activation of HSC. CTGF itself can promote cell adhesion and migration in a wide variety of cell types (38), induce fibroblast growth factor-mediated cell proliferation and insulin-like growth factor-promoted matrix synthesis (39) and enhance DNA synthesis in chondrocytes and osteoblasts (40). CTGF-knockout mice exhibited damaged chondrocyte proliferation and ECM composition (41). Fibroblasts obtained from CTGF-deficient mice featured impaired induction of TGF- $\beta$-induced adhesive signaling and were unable to respond to TGF- $\beta$ by inducing $\alpha$-SMA and collagen type I (42). Based on these previous studies, the present study hypothesized that visfatin-induced expression of collagen in HSC may be mediated by upregulating the expression of CTGF through TGF- $\beta$ signaling.

In conclusion, the present study provided evidence supporting the involvement of visfatin in HSC activation. However, the underlying mechanism remains to be elucidated. Visfatin may provide a novel potential therapeutic target for the treatment of hepatic cirrhosis, particularly in patients with obesity and/or diabetes.

\section{Acknowledgements}

This study was supported by the Chengdu City Science and Technology Bureau of Sichuan Province, China (no. 13PPYB994SF-014), the Science and Technology Department of Sichuan Province, China (nos. 2013FZ0085 and 2014CZ0002) and the National Natural Science Foundation of China (no. 11072163).

\section{References}

1. Bertolani $\mathrm{C}$ and Marra F: The role of adipokines in liver fibrosis. Pathophysiology 15: 91-101, 2008.

2. Wu D, Li H, Xiang G, et al: Adiponectin and its receptors in chronic hepatitis B patients with steatosis in china. Hepat Mon 13: e6065, 2013.

3. Tsochatzis EA, Papatheodoridis GV and Archimandritis AJ: Adipokines in nonalcoholic steatohepatitis: from pathogenesis to implications in diagnosis and therapy. Mediators Inflamm 2009: 831670,2009

4. Marra F and Bertolani C: Adipokines in liver diseases. Hepatology 50: 957-969, 2009.

5. Romacho T, Villalobos LA, Cercas E, Carraro R, Sanchez-Ferrer CF and Peiró C: Visfatin as a novel mediator released by inflamed human endothelial cells. PLoS One 8: e78283, 2013.

6. Van den Bergh R, Morin S, Sass HJ, et al: Monocytes contribute to differential immune pressure on R5 versus X4 HIV through the adipocy tokine visfatin/NAMPT. PLoS One 7: e35074, 2012.

7. Yu XY, Qiao SB, Guan HS, Liu SW and Meng XM: Effects of visfatin on proliferation and collagen synthesis in rat cardiac fibroblasts. Horm Metab Res 42: 507-513, 2010. 
8. Wang P, Xu TY, Guan YF, Su DF, Fan GR and Miao CY: Perivascular adipose tissue-derived visfatin is a vascular smooth muscle cell growth factor: role of nicotinamide mononucleotide. Cardiovasc Res 81: 370-380, 2009.

9. Song HK, Lee MH, Kim BK, et al: Visfatin: a new player in mesangial cell physiology and diabetic nephropathy. Am J Physiol Renal Physiol 295: F1485-F1494, 2008.

10. Liu XJ, Yang L, Mao YQ, et al: Effects of the tyrosine protein kinase inhibitor genistein on the proliferation, activation of cultured rat hepatic stellate cells. World J Gastroenterol 8: 739-745, 2002.

11. Friedman SL: Hepatic stellate cells: protean, multifunctional, and enigmatic cells of the liver. Physiol Rev 88: 125-172, 2008.

12. Nieto, N: A systems biology approach for understanding the collagen regulatory network in alcoholic liver disease. Liver Int 32: 189-198, 2012.

13. Zhu Y, Men R, Wen M, Hu X, Liu X and Yang L: Blockage of TRPM7 channel induces hepatic stellate cell death through endoplasmic reticulum stress-mediated apoptosis. Life Sci 94: 37-44, 2014.)

14. Liu XJ, Yang L, Wu HB, Qiang O, Huang MH and Wang YP: Apoptosis of rat hepatic stellate cells induced by anti-focal adhesion kinase antibody. World J Gastroenterol 8: 734-738, 2002

15. Kim JG, Kim EO, Jeong BR, et al: Visfatin stimulates proliferation of MCF-7 human breast cancer cells. Mol Cells 30: 341-345, 2010

16. Patel ST, Mistry T, Brown JE, et al: A novel role for the adipokine visfatin/pre-B cell colony-enhancing factor 1 in prostate carcinogenesis. Peptides 31: 51-57, 2010.

17. Höinghaus R, Hewicker-Trautwein $M$ and Mischke $R$ : Immunocytochemical differentiation of neoplastic and hyperplastic canine epithelial lesions in cytologic imprint preparations Vet J 173: 79-90, 2007.

18. Gilliver SC, Ruckshanthi JP, Atkinson SJ and Ashcroft GS: Androgens influence expression of matrix proteins and proteolytic factors during cutaneous wound healing. Lab Invest 87: 871-881, 2007.

19. Maeda E, Shelton JC, Bader DL and Lee DA: Differential regulation of gene expression in isolated tendon fascicles exposed to cyclic tensile strain in vitro. J Appl Physiol (1985) 106: 506-512, 2009.

20. Li L, Chen GP, Yang Y, Ye Y, Yao L and Hu SJ: Chronic inhibition of farnesyl pyrophosphate synthase attenuates cardiac hypertrophy and fibrosis in spontaneously hypertensive rats. Biochem Pharmacol 79: 399-406, 2010.

21. Chen A and Zheng S: Curcumin inhibits connective tissue growth factor gene expression in activated hepatic stellate cells in vitro by blocking NF-kappaB and ERK signalling. $\mathrm{Br}$ J Pharmacol 153: 557-567, 2008.

22. Dodig M, Ogunwale B, Dasarathy S, Li M, Wang BC and McCullough AJ: Differences in regulation of type I collagen synthesis in primary and passaged hepatic stellate cell cultures: the role of alpha5beta1-integrin. Am J Physiol Gastrointest Liver Physiol 293: G154-G164, 2007.

23. Troeger, J S, Mederacke I, Gwak G Y, Dapito D H, Mu X, Hsu C C, Pradere J P, et al: Deactivation of hepatic stellate cells during liver fibrosis resolution in mice. Gastroenterology 143: 10731083, e1022, 2012.

24. Ponomarenko, Y, Leo M A, Kroll W and Lieber C S: Effects of alcohol consumption on eight circulating markers of liver fibrosis. Alcohol and Alcoholism 37: 252-255, 2002

25. Cheng F, Li Y, Feng L and Li S: Hepatic stellate cell activation and hepatic fibrosis induced by ischemia/reperfusion injury. Transplant Proc 40: 2167-2170, 2008.
26. Gressner OA, Lahme B, Demirci I, Gressner AM and Weiskirchen R: Differential effects of TGF-beta on connective tissue growth factor (CTGF/CCN2) expression in hepatic stellate cells and hepatocytes. J Hepatol 47: 699-710, 2007.

27. Jiang JX, Mikami K, Shah VH and Torok NJ: Leptin induces phagocytosis of apoptotic bodies by hepatic stellate cells via a Rho guanosine triphosphatase-dependent mechanism. Hepatology 48: 1497-1505, 2008.

28. Kamada Y, Tamura S, Kiso S, et al: Enhanced carbon tetrachloride-induced liver fibrosis in mice lacking adiponectin. Gastroenterology 125: 1796-1807, 2003.

29. Adya R, Tan BK, Punn A, Chen J and Randeva HS: Visfatin induces human endothelial VEGF and MMP-2/9 production via MAPK and PI3K/Akt signalling pathways: novel insights into visfatin-induced angiogenesis. Cardiovasc Res 78: 356-365, 2008

30. Kim SR, Bae SK, Choi KS, et al: Visfatin promotes angiogenesis by activation of extracellular signal-regulated kinase $1 / 2$. Biochem Biophys Res Commun 357: 150-156, 2007.

31. Xie H, Tang SY, Luo XH, et al: Insulin-like effects of visfatin on human osteoblasts. Calcif Tissue Int 80: 201-210, 2007.

32. Brenner DA: Molecular pathogenesis of liver fibrosis. Trans Am Clin Climatol Assoc 120: 361-368, 2009.

33. Liu, Y, Liu H, Meyer C, Li J, Nadalin S, Konigsrainer A, Weng $\mathrm{H}$, et al: Transforming growth factor-beta (TGF-beta)-mediated connective tissue growth factor (CTGF) expression in hepatic stellate cells requires Stat 3 signaling activation. J Biol Chem 288: 30708-30719, 2013.

34. Paradis V, Dargere D, Bonvoust F, Vidaud M, Segarini P and Bedossa P: Effects and regulation of connective tissue growth factor on hepatic stellate cells. Lab Invest 82: 767-773, 2002.

35. Leask A, Holmes A, Black CM and Abraham DJ: Connective tissue growth factor gene regulation. Requirements for its induction by transforming growth factor-beta 2 in fibroblasts. J Biol Chem 278: 13008-13015, 2003.

36. Zheng S and Chen A: Curcumin suppresses the expression of extracellular matrix genes in activated hepatic stellate cells by inhibiting gene expression of connective tissue growth factor. Am J Physiol Gastrointest Liver Physiol 290: G883-G893, 2006.

37. Li G, Xie Q, Shi Y, et al: Inhibition of connective tissue growth factor by siRNA prevents liver fibrosis in rats. J Gene Med 8: 889-900, 2006.

38. Crean JK, Finlay D, Murphy M, et al: The role of p42/44 MAPK and protein kinase B in connective tissue growth factor induced extracellular matrix protein production, cell migration, and actin cytoskeletal rearrangement in human mesangial cells. J Biol Chem 277: 44187-44194, 2002.

39. Gore-Hyer E, Pannu J, Smith EA, Grotendorst G and Trojanowska M: Selective stimulation of collagen synthesis in the presence of costimulatory insulin signaling by connective tissue growth factor in scleroderma fibroblasts. Arthritis Rheum 48: 798-806, 2003

40. Kubota S and Takigawa M: Role of CCN2/CTGF/Hcs24 in bone growth. Int Rev Cytol 257: 1-41, 2007.

41. Ivkovic S, Yoon BS, Popoff SN, et al: Connective tissue growth factor coordinates chondrogenesis and angiogenesis during skeletal development. Development 130: 2779-2791, 2003.

42. Shi-wen X, Stanton LA, Kennedy L, et al: CCN2 is necessary for adhesive responses to transforming growth factor-beta1 in embryonic fibroblasts. J Biol Chem 281: 10715-10726, 2006. 